\title{
Initial Single-Site Experience Using SMILE for the Treatment of Astigmatism in Myopic Eyes and Comparison of Astigmatic Outcomes with Existing Literature
}

This article was published in the following Dove Press journal: Clinical Ophthalmology

\author{
Majid Moshirfar (iD ${ }^{1-3}$ \\ Andrew C Thomson (D) 4 \\ William B West $\mathrm{Jr}^{5}$ \\ MacGregor $\mathrm{N} \mathrm{Hall}^{4}$ \\ Shannon E McCabe iD \\ Robert J Thomson ${ }^{4}$ \\ Yasmyne C Ronquillo (D) \\ Phillip C Hoopes' \\ 'Hoopes Vision Research Center, \\ Hoopes Vision, Draper, UT, USA; 'John \\ A. Moran Eye Center, Department of \\ Ophthalmology and Visual Sciences, \\ University of Utah School of Medicine, \\ Salt Lake City, UT, USA; ${ }^{3}$ Utah Lions Eye \\ Bank, Murray, UT, USA; ${ }^{4}$ McGovern \\ Medical School at the University of Texas \\ Health Science Center at Houston, \\ Houston, TX, USA; ${ }^{5}$ University of Utah \\ School of Medicine, Salt Lake City, \\ UT, USA
}

Purpose: To assess a single site's initial experience with SMILE for the treatment of myopic astigmatism and compare outcomes and vector analysis results with the US Food and Drug Administration (FDA) results and published literature.

Patients and Methods: Forty-eight eyes (29 patients) with mean preoperative sphere of $-5.11 \pm 1.31$ diopters (D) and cylinder of $-1.12 \pm 0.60 \mathrm{D}$ underwent SMILE. Visual acuity, refractive, and vector analysis outcomes as well as subjective measures were reported at three and twelve months postoperatively and compared with FDA results and the published literature between 2014 and 2020 involving treatment of patients with mean cylinders of $>$ -0.50 to $\leq-3.00 \mathrm{D}$.

Results: At three and twelve months, 43 and 32 eyes were evaluated, respectively. At twelve months, mean cylinder power was reduced to $-0.38 \pm 0.38 \mathrm{D}$ with $78.1 \%$ achieving $\leq \pm 0.50$ D. Uncorrected distance visual acuity (UDVA) $\geq 20 / 20$ was achieved in $77.4 \%$ of eyes by twelve months with $100 \%$ achieving $\geq 20 / 30$ UDVA. No loss of corrected distance visual acuity was observed in eyes seen at twelve months. Correction index (CI) at twelve months was 0.90 indicating overall undercorrection of $10 \%$. Twelve-month CI was $0.96,0.90$, and 0.83 in eyes with preoperative cylinders of $<-1.00 \mathrm{D}, \geq-1.00$ to $<-2.00 \mathrm{D}$, and $\geq-2.00 \mathrm{D}$, respectively. Mean angle of error was $-1.58 \pm 11.61^{\circ}$ ranging from $-24.22^{\circ}$ to $37.75^{\circ}$.

Conclusion: We found SMILE to be an effective and safe means of achieving spectacle independence and improving visual acuity in patients with myopic astigmatism. SMILE has the potential for improved clinical outcomes with better nomogram guidance and advancements in technique. However, surgeons must be aware of the potential for undercorrection in with-the-rule astigmatism and at higher preoperative cylinders and as well as the potential for overcorrection in against-the-rule and lower preoperative cylinder astigmatism.

Keywords: SMILE, myopia, astigmatism, vector analysis, ReLEx, toric

\section{Introduction}

Femtosecond lenticule extraction (FLEx) was introduced by Sekundo et al using a femtosecond laser (VisuMax, Carl Zeiss Meditec, Jena, Germany) with the ability to create both an intrastromal refractive lenticule and a corneal flap for lenticule removal. ${ }^{1}$ By 2011, refinement of this technique led to small-incision lenticule extraction (SMILE) which removes the lenticule via a small 2-3 $\mathrm{mm}$ incision for the treatment of myopia and myopic astigmatism. ${ }^{2-4}$ SMILE was approved by the
Correspondence: Majid Moshirfar Hoopes Vision Research Center, II820 S. State Street Suite \#200, Draper, UT 84020 , USA

Tel + I 80I-568-0200

$\mathrm{Fax}+1$ 80I-563-0200

Email cornea2020@me.com 
US Food and Drug Administration (FDA) for the treatment of simple myopia in 2016, and has been used to effectively treat mild to moderate myopia with comparable efficacy, safety, and predictability to femtosecond laserassisted in situ keratomileusis (FS-LASIK). ${ }^{5,6}$ In 2018, the US FDA approved SMILE for the treatment of myopic astigmatism from $>-0.50$ to $\leq-3.00$ diopters (D), ${ }^{7}$ and the use of SMILE for this indication has since been further investigated. ${ }^{8-24}$ Previous studies on the treatment of astigmatism with SMILE have found that it is safe and effective, but these studies were conducted outside of the United States. Our study will assess a single site's initial experience with SMILE for the treatment of myopic astigmatism and compare outcomes with FDA results and published literature.

\section{Materials and Methods}

A non-randomized retrospective study was conducted using de-identified data from the medical records of 29 patients (48 eyes). Ten patients underwent unilateral SMILE for correction of myopic astigmatism, and 19 underwent this procedure bilaterally resulting in 48 total eyes. Procedures were performed between October 2018 and June 2020 at a refractive surgery center in Draper, UT, USA. All procedures and methods followed the ethical standards of the Helsinki Declaration and later amendments, and the study was approved by the Hoopes Vision Research Review Board. All patients were fully informed and consented to treatment. Participants underwent refractive screening consultation, and any patients with an ocular history of glaucoma, herpes zoster ophthalmicus, herpes simplex keratitis, prior cataract surgery, or abnormal topography were excluded.

Postoperative visits occurred at one day, one week, three months, six months, and twelve months. Postoperative measurements and complications were reported, and vector analysis was performed. These outcomes were compared with those found on the 2018 FDA Summary of Safety and Effectiveness Data report obtained from FDA.gov as well as the twelve month results of this same premarket approval trial as reported by Dishler et al.${ }^{7,11}$ Results were also compared with other studies between 2014 and 2020 that involved treatment of patients with preoperative cylinders of $>-0.50 \mathrm{D}$ or $\leq-3.00 \mathrm{D}$ and reported visual acuity, refractive, or vector analysis outcomes at three or twelve months postoperatively.

Postoperative complications were assessed by slit lamp examination and physician interview, and three- and twelve-month results were reported. Dry eye symptoms were categorized as either mild (intermittent symptoms), moderate (daily symptoms relieved by lubricating eye drops), or severe (refractory symptoms requiring lifitegrast or cyclosporine) dry eye disease (DED). The presence of superficial punctate keratitis (SPK) was reported and graded via a nominal scale with $0,1+, 2+$, and $3+$ denoting no, mild, moderate, and significant corneal staining, respectively.

\section{Surgical Procedure}

SMILE was performed using the Visumax $500 \mathrm{kHz}$ femtosecond laser (Carl Zeiss Meditec, Jena, Germany). A surgical marking pen was used to mark the limbus at 3 and 9 o'clock preoperatively while the patient was seated in an upright position. The patient was then taken to the operating room and placed in a supine position. Using a caliper set at $8 \mathrm{~mm}$, the cornea was marked inside the limbus at the corresponding 3 and 9 o'clock limbal markings. If any cyclotorsion was noted after application of the vacuum, the interface cone was gently rotated manually clockwise or counter-clockwise to align the corresponding marks on the cornea with the horizontal reticule on the laser scope. Surgical parameters were set with a cap thickness of $120 \mu \mathrm{m}$ and cap diameter of $7.5 \mathrm{~mm}$. Hinge placement was superior with hinge angle at 60 degrees and side-cut angle of 90 degrees. Lenticule diameter was $6.5 \mathrm{~mm}$. Spot separation was $4.4 \mu \mathrm{m}$ for the lenticule, 2.0 $\mu \mathrm{m}$ for the lenticule side-cut, $3.0 \mu \mathrm{m}$ for the flap, and 2.0 $\mu \mathrm{m}$ for the flap side cut. Laser-bed energy was set at 130 nJ. Postoperatively, patients were prescribed fluoroquinolone antibiotic drops to be used 4 times daily for one week and a $1 \%$ prednisolone taper of $4,3,2$, and 1 drops per day for one week each.

\section{Vector Analysis}

Astigmatic vector analysis was performed following the Alpins method and terminology. ${ }^{25-27}$ Manifest refraction data were converted to the corneal plane with a backvertex distance of $12 \mathrm{~mm}$. Target induced astigmatism (TIA) and surgically induced astigmatism (SIA) are defined as intended and actual astigmatic change with the goal of emmetropia. The difference vector (DV) is the difference between TIA and SIA vectors and represents the residual uncorrected astigmatism, whereas the magnitude of error (ME) is the arithmetic difference between TIA and SIA. Angle of error is the angle between TIA and SIA. The corrective index (CI) is the ratio of SIA to TIA 
and is ideally equal to one. The percentage of astigmatism corrected may also be calculated by CI x $100 \%{ }^{27}$ Averaged CI values may be found by calculating the geometric mean. Of note, the corresponding geometric standard deviation (SD) is a unitless value and must multiply or divide the geometric mean to describe the $68 \%$ confidence interval. ${ }^{28}$

\section{Results}

\section{Patient Demographics}

SMILE was performed on 48 eyes, 24 left and right, from 29 patients. At three-month and twelve-month visits, 43 eyes $(89.6 \%)$ and 32 eyes $(66.7 \%)$ were seen, respectively. Out of the 29 patients, 11 (16 eyes) have not yet completed their twelve-month visit. Three patients (5 eyes), who were not seen at an approximately three-month visit, had completed twelve-month visits. Preoperative manifest sphere and cylinder ranged from -6.75 to $-2.50 \mathrm{D}$ and -2.50 to $-0.50 \mathrm{D}$, respectively. All patients had 20/20 or better corrected distance visual acuity (CDVA) before surgery. With-the-rule (WTR) astigmatism was found in 27 eyes (56\%), and 11 eyes (23\%) had against-the-rule (ATR) astigmatism. Pre- and postoperative measurements obtained at three months and twelve months are displayed in Table 1. Visual acuity and manifest refraction were obtained preoperatively and postoperatively, and data were summarized with standard outcome reporting (Figure 1). ${ }^{30}$

\section{Efficacy and Visual Acuity}

Only eyes with a plano target were included in visual acuity reporting. At twelve months, $77.4 \%$ of eyes achieved $20 / 20$ or better uncorrected distance visual acuity (UDVA) and $100 \%$ had $20 / 30$ or better UDVA (Figure 1A). At three months, UDVA of $20 / 20$ and $20 / 30$ or better was achieved in $84.2 \%$ and $100 \%$ of eyes, respectively. Comparisons of postoperative UDVA and CDVA values are depicted in Figure 2B. At three months, $7.0 \%$ of eyes had a loss of one Snellen line in CDVA, but there was no loss of CDVA in any eyes seen at 12 months (Figure 1C). No change in CDVA was demonstrated in most eyes seen at three months (67.4\%) and twelve months (87.5\%) while $25.6 \%$ and $12.5 \%$ of eyes gained one line at three and twelve months, respectively.

\section{Accuracy and Stability}

Postoperative manifest spherical equivalent (MSE) within $\pm 1.00 \mathrm{D}$ of target was seen in $97.7 \%$ of eyes at three months and $100 \%$ of eyes at twelve months. MSE within $\pm 0.50 \mathrm{D}$ of intended target were demonstrated in $88.4 \%$ and $84.4 \%$ of eyes at three and twelve months, respectively (Figure 1D). The mean MSE was relatively stable from six months to twelve months with a change of $>0.50$ D observed in only 9 eyes (19.0\%) (Figure 1E).

\section{Astigmatism Analysis}

Refractive astigmatism at three and twelve months is presented in Figure 1F. Mean cylinder refraction showed refractive regression after one week (Figure 1G). By twelve months, mean cylinder refractive error was -0.38 $\pm 0.38 \mathrm{D}$.

Vector analysis was performed on refractive measurements adjusted to a back-vertex distance of $12 \mathrm{~mm}$. The overall mean TIA, which corresponds to preoperative astigmatism, of the eyes seen at three-month visits was $0.92 \pm 0.48 \mathrm{D}$ ranging from 1.69 to $2.14 \mathrm{D}$. Three months after surgery, the overall mean SIA was close to TIA at $0.92 \pm 0.43 \mathrm{D}(0.33$ to $2.21 \mathrm{D})$. For twelve-month visits, overall TIA was $1.08 \pm 0.54 \mathrm{D}(0.44$ to $2.14 \mathrm{D})$ and overall SIA was $1.01 \pm 0.51 \mathrm{D}(0.22$ to $2.12 \mathrm{D})$. The geometric mean of $\mathrm{CI}$ at three months was 1.00 (0.41 to 2.38), and at twelve months, it was 0.90 ( 0.18 to 2.27$)$. This means no overall astigmatism undercorrection was seen at three months, and $10 \%$ undercorrection was seen at twelve months. However, with data stratified by preoperative cylinder power (Table 2), higher amounts of preoperative astigmatism tended to be undercorrected, whereas lower amounts of astigmatism tended to be overcorrected. Scatter plot analysis with regression lines of three- and twelve-month TIAs and SIAs are displayed in Figure $1 \mathrm{H}$. For both time points, overall absolute overcorrection is evident on the regression line equations seen as a positive y-intercept. The slopes for both time points are less than one which represents overall relative undercorrection per diopter of target induced astigmatism of $32 \%$ $\left(\mathrm{R}^{2}=0.564\right)$ for three months and $33 \%\left(\mathrm{R}^{2}=0.513\right)$ for twelve months. Analysis of the angle of error for twelvemonth results showed overall arithmetic mean of $-1.58 \pm$ $11.61^{\circ}\left(-24.22^{\circ}\right.$ to $\left.37.75^{\circ}\right)$ with absolute mean of $7.04 \pm$ $9.28^{\circ}$ (Figure 1I).

Double angle vector diagrams (DAVD) were created using the ASSORT $^{\circledR}$ Group Analysis Calculator in plus cylinder power. Angles were doubled, so TIA vectors between $120^{\circ}$ and $240^{\circ}$ represent treatment of ATR astigmatism, and between $60^{\circ}$ and $300^{\circ}$ signify treatment of WTR astigmatism. Postoperative changes equate to 
Table I Preoperative Data and Outcomes at Three and Twelve Months

\begin{tabular}{|c|c|c|c|}
\hline Outcomes & Preoperative & 3 Months & 12 Months \\
\hline CDVA (logMAR) & $n=43^{a}$ & $\mathrm{n}=38^{\mathrm{a}}$ & $n=31^{a}$ \\
\hline Mean \pm SD & $-0.02 \pm 0.04$ & $-0.03 \pm 0.05$ & $-0.03 \pm 0.04$ \\
\hline Range & $(-0.1$ to 0$)$ & $(-0.12$ to +0.10$)$ & $(-0.12,0.00)$ \\
\hline UDVA (logMAR) & - & $\mathrm{n}=38^{\mathrm{a}}$ & $n=3 I^{a}$ \\
\hline Mean $\pm S D$ & - & $0.04 \pm 0.12$ & $0.11 \pm 0.08$ \\
\hline Range & - & $(-0.10$ to +0.60$)$ & $(-0.12$ to +0.20$)$ \\
\hline Sphere (D) & $n=48$ & $n=43$ & $n=32$ \\
\hline Mean \pm SD & $-5.1| \pm| .3 \mid$ & $0.06 \pm 0.52$ & $0.20 \pm 0.40$ \\
\hline Range & $(-6.75$ to -2.50$)$ & $(-1.50$ to +1.00$)$ & $(-0.75$ to +1.00$)$ \\
\hline Cylinder (D) & $n=48$ & $n=43$ & $n=32$ \\
\hline Mean $\pm S D$ & $-1.12 \pm 0.60$ & $-0.44 \pm 0.39$ & $-0.38 \pm 0.38$ \\
\hline Range & $(-2.5$ to -0.50$)$ & $(-2.00$ to 0.00$)$ & $(-1.25$ to 0$)$ \\
\hline$\leq 0.50 \mathrm{D}(\%)$ & - & 81.4 & 78.1 \\
\hline$\leq 1.00 \mathrm{D}(\%)$ & - & 97.7 & 93.8 \\
\hline MSE (D) & $n=48$ & $n=43$ & $n=32$ \\
\hline Mean \pm SD & $-5.67 \pm 1.40$ & $-0.16 \pm 0.55$ & $0.01 \pm 0.42$ \\
\hline Range & $(-7.62$ to -2.87$)$ & $(-1.75$ to +0.75$)$ & $(-0.88$ to +0.88$)$ \\
\hline $\pm 0.50 \mathrm{D}$ of Intended $(\%)$ & - & 88.4 & 84.4 \\
\hline$\pm \mathrm{I} .00 \mathrm{D}$ of Intended (\%) & - & 97.7 & 100 \\
\hline \multicolumn{4}{|l|}{ Efficacy index } \\
\hline Mean $\pm S D$ & - & $1.12 \pm 0.53$ & $1.05 \pm 0.25$ \\
\hline \multicolumn{4}{|l|}{ Safety index } \\
\hline Mean \pm SD & - & $0.95 \pm 0.12$ & $0.97 \pm 0.07$ \\
\hline Ocular Diseases & $\mathrm{n}=48$ & $n=43$ & $n=32$ \\
\hline DED ${ }^{\mathrm{b}}$, no. (\%) & 21 (44\%) & $20(47 \%)$ & $10(38 \%)$ \\
\hline Mild, no. (\%) & 0 & II (26\%) & $8(25 \%)$ \\
\hline Moderate, no. (\%) & 0 & $9(21 \%)$ & $2(6 \%)$ \\
\hline Severe, no. (\%) & 0 & 0 & $2(6 \%)$ \\
\hline SPK', no (\%) & $5(10 \%)$ & $7(16 \%)$ & $3(9 \%)$ \\
\hline Haze $^{\mathrm{d}}$, no. (\%) & 0 & $7(16 \%)$ & $5(16 \%)$ \\
\hline
\end{tabular}

Notes: ${ }^{a}$ Only eyes with plano refractive targets were considered for visual acuity calculations. ${ }^{b} \mathrm{DED}$ was categorized as either mild (intermittent symptoms), moderate (daily symptoms relieved by lubricating eye drops), or severe (refractory symptoms requiring lifitegrast or cyclosporine). ${ }^{\mathrm{c}, \mathrm{d}}$ Incidences of any SPK or haze noted on slit lamp examination at respective time points are listed.

Abbreviations: CDVA, corrected distance visual acuity; SD, standard deviation; UDVA, uncorrected distance visual acuity; D, diopter; MSE, manifest spherical equivalent; DED, dry eye disease; SPK, superficial punctate keratitis.

corneal flattening at the power meridian as described by Holliday et al. ${ }^{29}$ Vector means, also known as centroids, are displayed as red diamonds on the DAVD. Three- and twelve-month TIA and difference vectors are displayed with confidence ellipses (Figure 2). With more vectors appearing between $60^{\circ}$ and $300^{\circ}$, attempted correction of eyes with WTR astigmatism appears to predominate. Smaller confidence ellipse and centroid mean magnitude in the DV compared to TIA DVAD represents correction being achieved. The difference vector centroid magnitude at twelve months was $0.21 \mathrm{D}$ with an axis of $5^{\circ}$.

\section{Subjective Measures and Clinical Findings}

Mild to moderate DED was observed in $44 \%$ of eyes preoperatively and remained relatively unchanged by three months at $47 \%$. By twelve months, total DED incidence was even lower at $38 \%$. Two eyes $(6 \%)$ from one patient required lifitegrast for severe DED. Some degree of haze was noted on slit lamp examination in $16 \%$ of eyes at twelve-month visits, but these findings were not visually significant as there was no loss of CDVA lines. Grade 1+ to $2+$ SPK was seen in $10 \%$ of eyes preoperatively and appears to have increased in prevalence at three months 


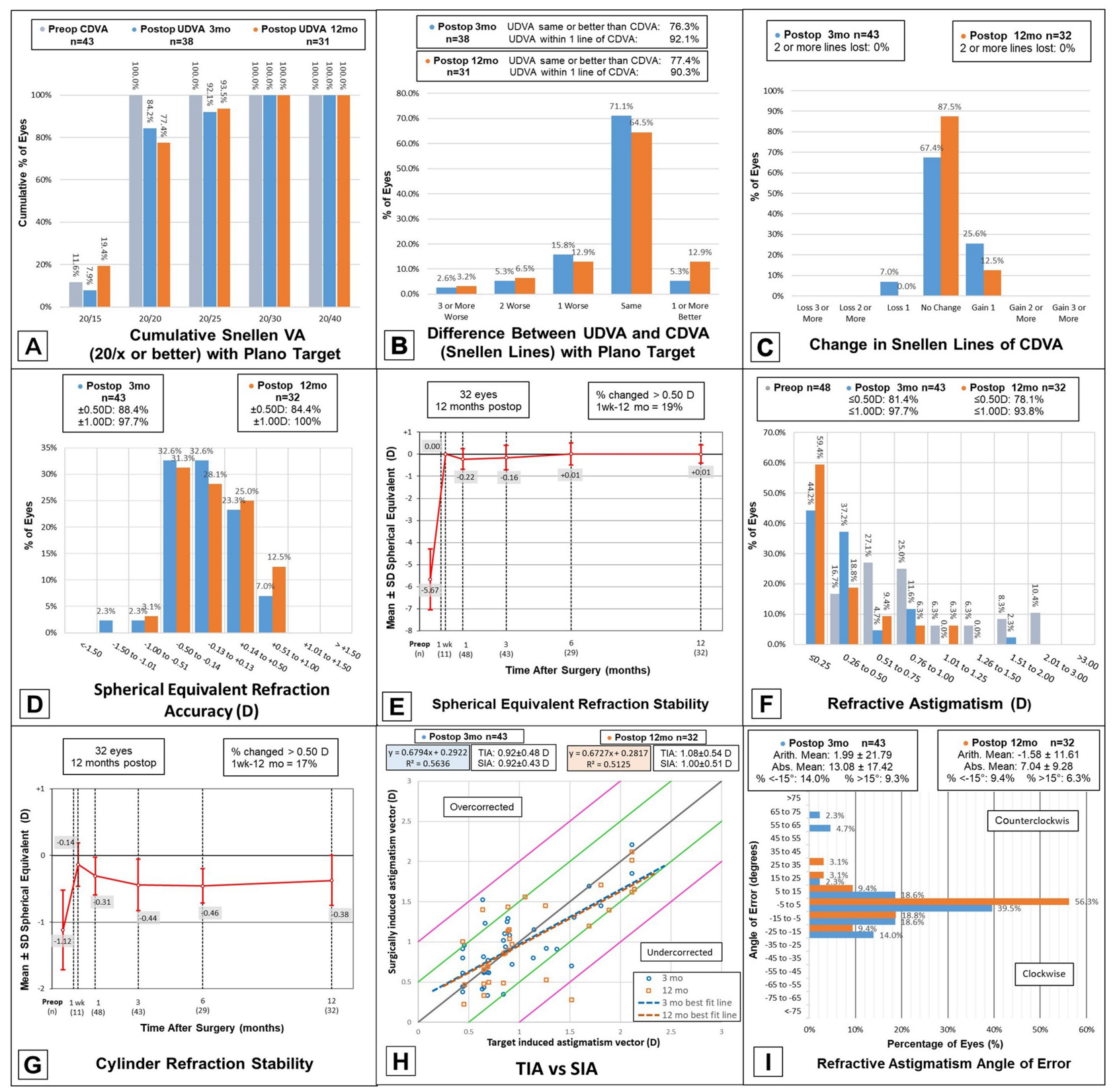

Figure I Standard reporting graphs for three- and twelve-month outcomes of eyes treated with SMILE.

Notes: (A) cumulative UDVA; (B) UDVA vs CDVA; (C) change in CDVA; (D) spherical equivalent refraction accuracy; (E) spherical equivalent stability; (F) refractive astigmatism; (G) cylinder refraction stability; $(\mathbf{H})$ TIA vs SIA; (I) refractive astigmatism angle of error. In $(\mathbf{H})$ green and purple lines represent $0.5 \mathrm{D}$ and I.0 D, respectively. Abbreviations: preop, preoperative; UDVA, uncorrected distance visual acuity; CDVA, corrected distance visual acuity; postop, postoperative; SD, standard deviation; SIA, surgically induced astigmatism; TIA, target induced astigmatism.

$(16 \%)$ but was closer to preoperative rates by twelve months $(9 \%)$ with no change in grade ranges. No intraoperative events were noted other than minor corneal abrasions and epithelial defects which resolved immediately.

\section{Discussion}

Preoperative patient characteristics were comparable to those in the FDA clinical trial of myopic astigmatic
SMILE in terms of age, mean cylinder, and mean MSE $;{ }^{711}$ however, the FDA study involved substantially more eyes (304) and reported the treatment of larger refractive ranges (Table 3). Narrow MSE stability and accurate correction were observed in both studies. A smaller postoperative spherical equivalent was seen at twelve months in the FDA study with $17.3 \%$ more eyes within $\pm 0.50 \mathrm{D}$ of target. A greater degree of UDVA 


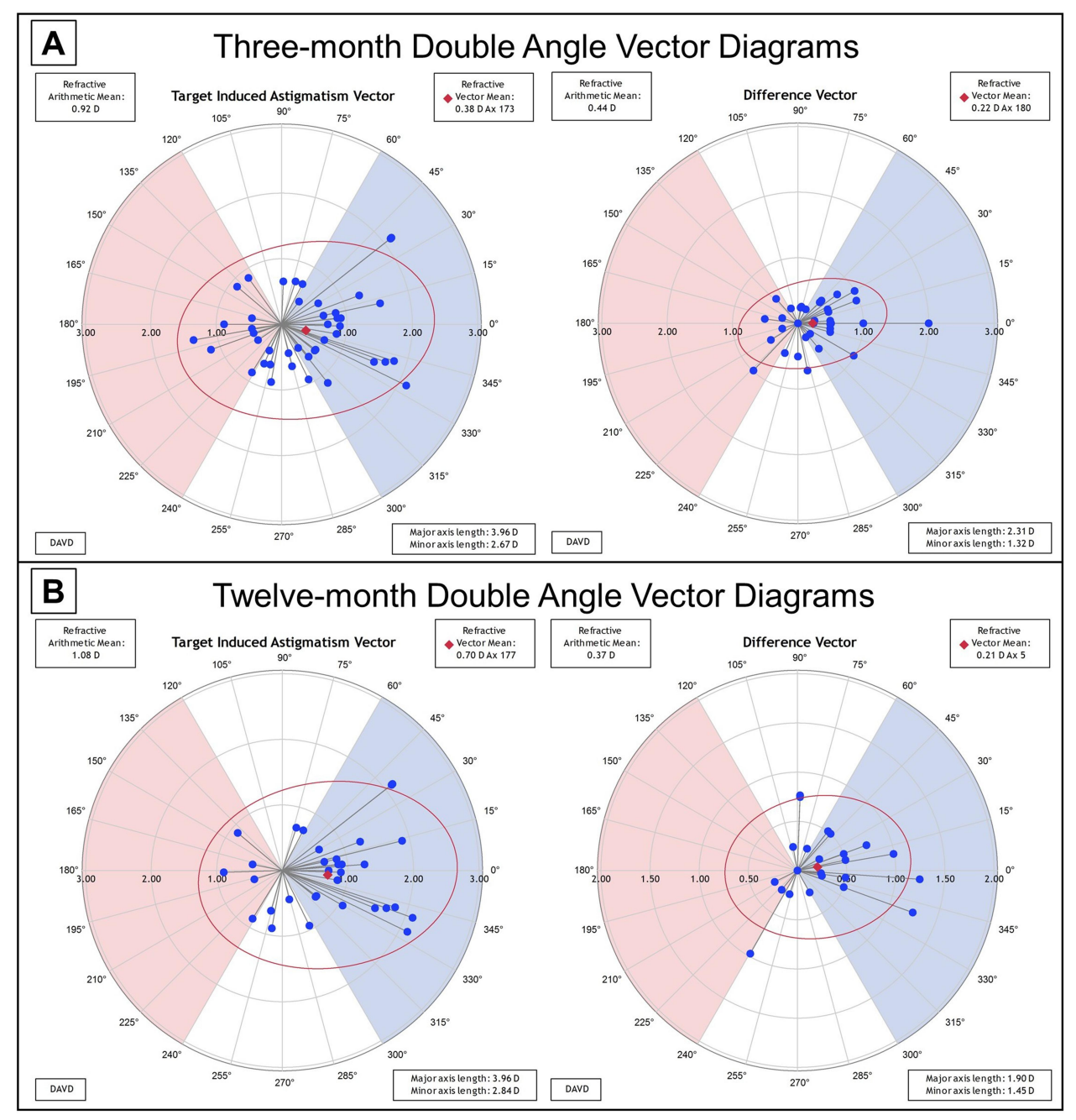

Figure 2 Double angle vector diagrams for three- and twelve-month target induced astigmatism and difference vector.

Notes: (A) Three-month DAVD; (B) Twelve-month DAVD. Vector magnitudes represent plus cylinder power in diopters. Angles have been doubled. Target induced astigmatism vectors are perpendicular to patient astigmatism, so vectors with angles between $60^{\circ}$ and $300^{\circ}$ in the blue field represent the treatment of with-the-rule astigmatism.

Abbreviations: DAVD, double angle vector diagram; D, diopter; Ax, axis.

improvement was achieved in the FDA study with 59.3\% of eyes achieving 20/16 or better, but both studies had comparable rates of $20 / 25$ or better. Of note, visual acuity in our study was evaluated using the Snellen chart rather than the ETDRS chart. Our results showed $19.4 \%$ of eyes achieved 20/15 at one year, and patients were not routinely asked to read below 20/15. In the FDA study, 10\% more eyes gained one line in CDVA compared to ours (12.5\%).

Better mean cylinder correction was achieved in the FDA study, $-1.53 \pm 0.70 \mathrm{D}$ decreasing to $-0.18 \pm 0.31 \mathrm{D}$, with $91.7 \%$ achieving $\leq \pm 0.50 \mathrm{D}$ versus $84 \%$ in this study. Stability was considerably better as well with less final residual astigmatism. Mean TIA and SIA were larger in the FDA study meaning higher amounts of astigmatism were corrected. Analysis of scatter plot regression lines of TIA versus SIA shows the FDA study achieved better and more consistent astigmatic correction with a slope of $0.856\left(\mathrm{R}^{2}\right.$ $=0.865$ ).

The difference in results achieved in the FDA study and this study may be due to several reasons. The FDA study had a much larger sample size and therefore less potential influence by outliers. Patient follow-up was higher in the FDA study as well. The authors of the FDA study attributed the use of wavefront refractions to obtain accurate astigmatism and axis measurements as a potential factor for improved results as well. ${ }^{11}$ Our study only utilized manifest refraction values. The FDA study does not mention preoperative adjustment or use of nomogram values, so it is unclear if this was an additional factor influencing result. 


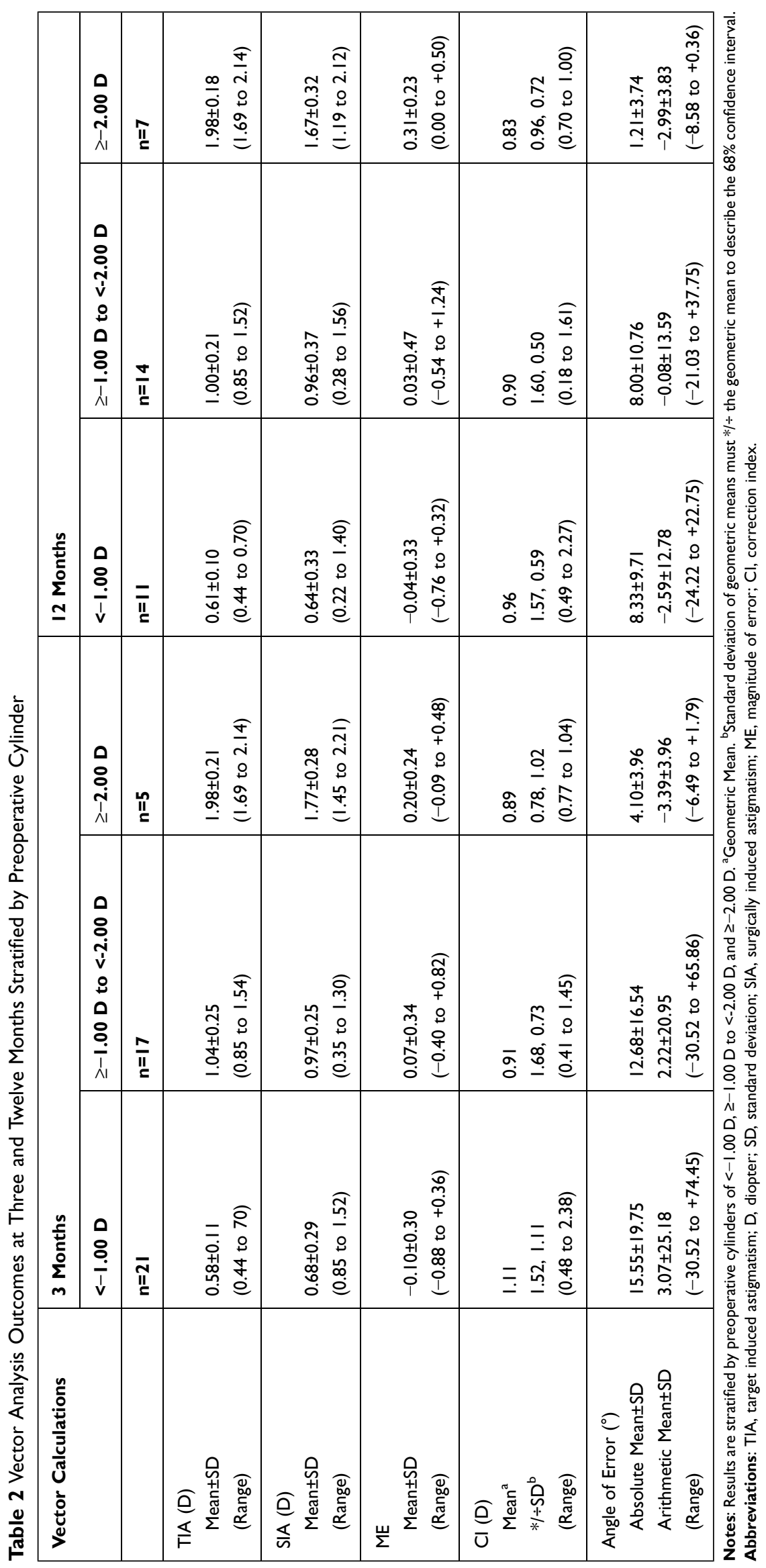




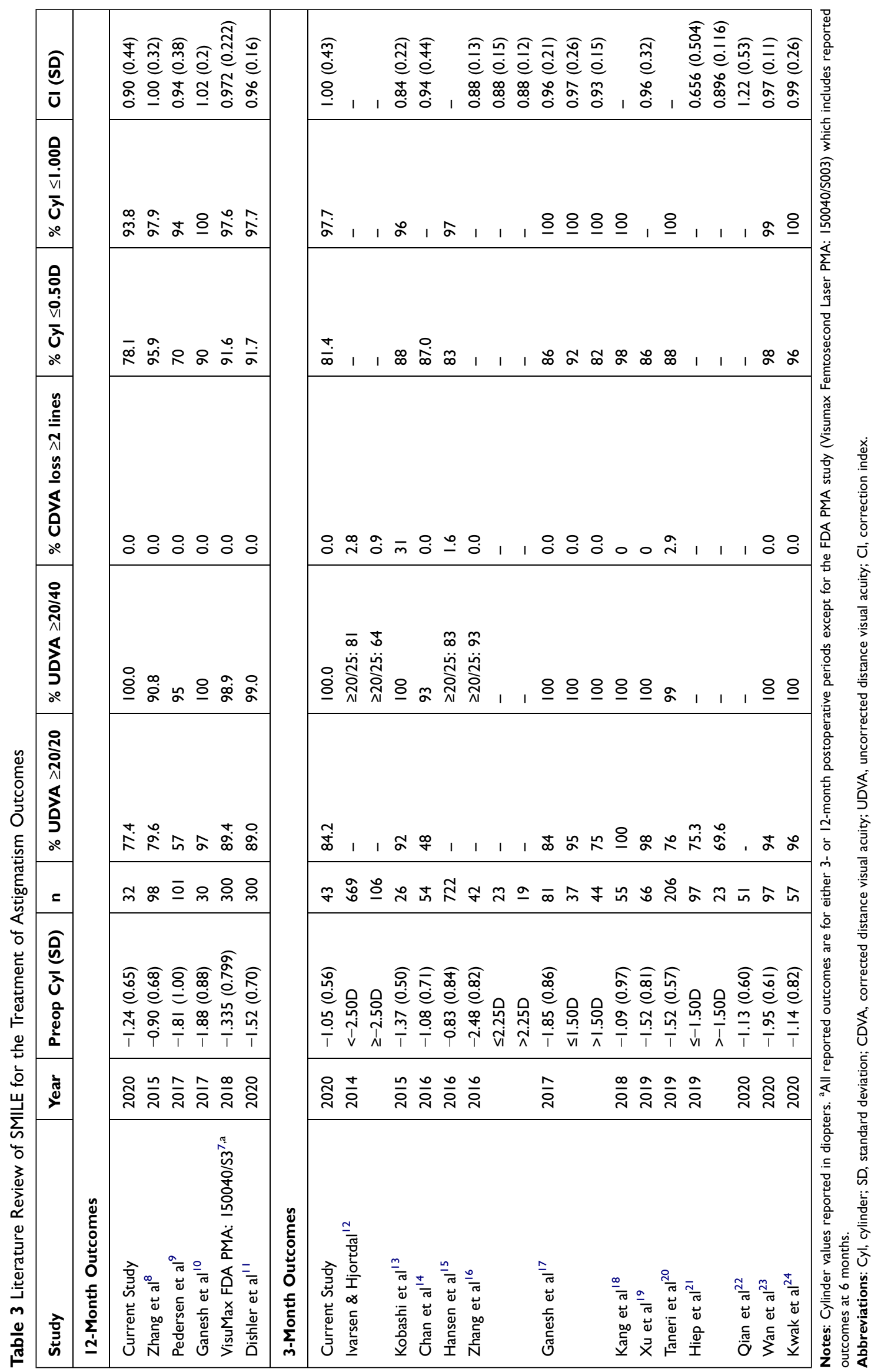




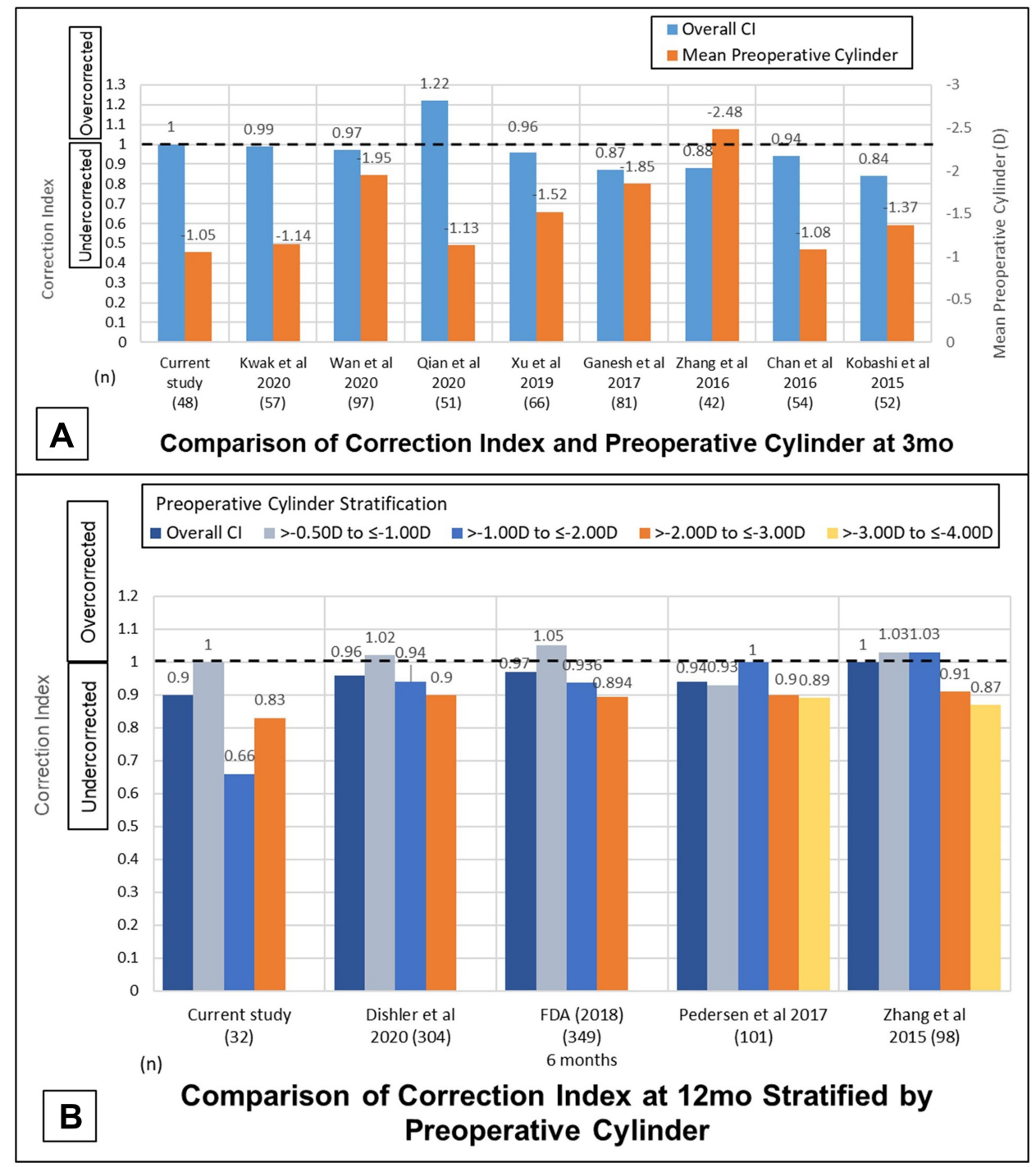

Figure 3 Comparison of vector analysis outcomes with other studies.

Notes: (A) Comparison of correction index and preoperative cylinder at 3 months. (B) Comparison of correction index at 12 months stratified by preoperative cylinder. Dashed lines represent a correction index of $\mathrm{I}$.

Abbreviations: $\mathrm{Cl}$, correction index; $\mathrm{D}$, diopter.

Upon vector analysis, undercorrection becomes evident when attempting to treat high astigmatism $(\geq-1.00$ D) and overcorrection when attempting to treat low astigmatism $(<-1.00 \mathrm{D})$, and similar trends of undercorrecting higher amounts of astigmatism and overcorrecting lower amounts have been reported in other studies (Figure 3). ${ }^{31,32}$ When stratified by preoperative cylinder at twelve months, there was $4 \%$ undercorrection for eyes with $<-1.00 \mathrm{D}$ of astigmatism $(\mathrm{n}=11), 10 \%$ in eyes with $\geq-1.00 \mathrm{D}$ to $-2.00 \mathrm{D}(\mathrm{n}=14)$, and $17 \%$ in eyes with $\geq-2.00 \mathrm{D}(\mathrm{n}=7)$. At twelve months, the FDA reported overall astigmatism undercorrection of $4 \%$ versus this study's finding of $10 \% .^{11}$ Undercorrection reported in previous studies ranges from around $10-15 \%$ which is in agreement with our study. ${ }^{8-}$ $10,12,31-34$

A benefit of vector analysis over the use of MSE in astigmatic outcomes is appreciating the changes in the axis of astigmatism. Inadequate adjustment for cyclotorsion leads to increasing angles of error and potentially poorer visual outcomes. ${ }^{35}$ Unlike other devices used in LASIK or PRK, the current Visumax platform for SMILE does not have robust, built-in cyclotorsion control. However, image-guided systems and surgical techniques for centration and axis alignment have been used in SMILE with promising results. ${ }^{36,37}$ 
An association between with-the-rule (WTR) astigmatism and undercorrection, when compared to against-therule (ATR) or oblique astigmatism, has been well described. ${ }^{31,32}$ This was also observed in our study as geometric means of CI in eyes with WTR astigmatism ( 0.85 at three months and 0.78 at twelve) were lower than those seen in eyes with ATR (1.15 and 1.36) or oblique (1.25 and 1.05) astigmatism. This signifies that at twelve months, WTR eyes $(\mathrm{n}=21)$ were undercorrected by $22 \%$ and ATR eyes $(n=5)$ were overcorrected by $36 \%$. This finding may also be seen on the double angle vector diagram (DAVD) of the difference vectors (DV) for three and twelve months as the centroid vectors have angles near or at $0^{\circ}$ representing further correction is required for plus cylinder astigmatisms between $60^{\circ}$ and $120^{\circ}$ (Figure 2). A potential confounder is that mean preoperative cylinder for ATR, $-0.80 \pm 0.27 \mathrm{D}$, was smaller than WTR, $-1.48 \pm 0.68$ D. However, when only similar preoperative cylinders are considered, mean preoperative cylinder for WTR was $-0.88 \pm 0.13 \mathrm{D}$ at twelve months, and the geometric mean of $\mathrm{CI}$ for these eyes showed undercorrection of $13 \%$. The preponderance of WTR astigmatism in this study may provide some explanation as to the overall undercorrection seen in these results. Iversen et al found a difference of around $0.35 \mathrm{D}$ in postoperative cylinder between WTR and ATR correction, and suggested adding $0.125 \mathrm{D}$ per diopter of WTR astigmatism and a constant $0.25 \mathrm{D}$ undercorrection of ATR astigmatism. $^{31}$

Without the need for flap creation, SMILE appears to have decreased risk of inducing or worsening DED when compared to LASIK. ${ }^{38}$ In our study, DED incidence was below baseline by twelve months. Only one patient seen in this study required more than daily lubricating eye drops for symptomatic relief after surgery, and one patient complaining of "moderate" symptoms had received punctal plugs. Of note, dry eye analysis did not use objective measures making these findings difficult to compare with other studies.

This study was limited as a non-randomized retrospective study. There was also a small patient cohort with a low rate of twelve-month follow up and resulting vulnerability to outliers. For example, the mean twelve-month CI for preoperative cylinders ranging from $>-0.50 \mathrm{D}$ to $\leq-1.00 \mathrm{D}$ is 0.86 rather than 0.66 when one outlier is removed. Most patients in this study had preoperative astigmatism less than $-2.00 \mathrm{D}$, so the overall results may be over-estimated when compared to other studies performing treatments on higher levels of astigmatism. Intra-operative cyclotorsion requiring manual compensation was also not recorded in this study. Although operations were carried out by experienced surgeons, SMILE techniques are different from that of routine flap based refractive surgeries, so results in this study may be influenced by an initial phase learning curve. ${ }^{39}$

Nomograms rely on data gathered from previous cases to determine which modifications to target refraction are required to meet desired outcomes and are therefore of limited aid during initial experiences with new surgical techniques. As nomogram adjustments were available for the treatment of simple myopia at the time of this study, but not for the treatment of astigmatism, it is reasonable to expect an improvement in refractive outcomes as more postoperative data is gathered. The coefficient of adjustment (CA), defined as is the ratio of TIA to SIA, may help to increase refractive accuracy. ${ }^{25}$ For this study, the CA for eyes with preoperative cylinders $\geq-1.00 \mathrm{D}$ was $10 \%$ for twelve-month results. Ganesh et al showed improved refractive accuracy with manual cyclotorsion compensation and a similar $10 \%$ increase in correction when they compared with previous results. ${ }^{10}$ However, further adjustment may be necessary based upon whether a patient has WTR or ATR astigmatism.

\section{Conclusion}

Although our results differ from some recent studies, outcomes achieved were promising with $77.4 \%$ of eyes achieving UDVA equal to or better than preoperative CDVA with $19.4 \%$ of eyes achieving UDVA of 20/15. These results are comparable to others in the literature and surpass the FDA guidance recommended targets for visual acuity and refractive outcomes. After this initial experience, nomogram adjustments are possible. Better cyclotorsion control may also lead to a decrease in angles of error and improved visual outcomes. In conclusion, this study finds SMILE to be a safe and effective method of correction for myopic astigmatism, but surgeons must be cognizant of the potential for undercorrection in WTR astigmatism at higher preoperative cylinders as well as the potential for overcorrection in ATR astigmatism and at lower preoperative cylinders.

\section{Disclosure}

The authors report no conflicts of interest in this work. 


\section{References}

1. Sekundo W, Kunert K, Russmann C, et al. First efficacy and safety study of femtosecond lenticule extraction for the correction of myopia. Six-month results. J Cataract Refract Surg. 2008;34 (9):1513-1520. doi:10.1016/j.jcrs.2008.05.033

2. Sekundo W, Kunert KS, Blum M. Small incision corneal refractive surgery using the small incision lenticule extraction (SMILE) procedure for the correction of myopia and myopic astigmatism: results of a 6 month prospective study. Br J Ophthalmol. 2011;95(3):335-339. doi:10.1136/bjo.2009.174284

3. Reinstein DZ, Archer TJ, Gobbe M. Small incision lenticule extraction (SMILE) history, fundamentals of a new refractive surgery technique and clinical outcomes. Eye Vis. 2014;1(1):3. doi:10.1186/ s40662-014-0003-1

4. Moshirfar M, McCaughey MV, Reinstein DZ, Shah R, SantiagoCaban L, Fenzl CR. Small-incision lenticule extraction. J Cataract Refract Surg. 2015;41(3):652-665. doi:10.1016/j.jcrs.2015.02.006

5. Zhang Y, Shen Q, Jia Y, Zhou D, Zhou J. Clinical outcomes of SMILE and FS-LASIK used to treat myopia: a meta-analysis. J Refract Surg. 2016;32(4):256-265. doi:10.3928/1081597X-20151111-06

6. Shah R. History and Results; Indications and Contraindications of SMILE Compared With LASIK. Asia-Pacific $J$ Ophthalmol (Philadelphia, $\quad P a$ ). 2019;8(5):371-376. doi:10.1097/01. APO.0000580132.98159.fa

7. United States Food and Drug Administration. Premarket approval study: visuMax femtosecond laser lenticule removal procedure for the correction with or without astigmatism. Available from: https:// www.accessdata.fda.gov/cdrh_docs/pdf15/p150040s003a.pdf. Accessed September 18, 2020.

8. Zhang J, Wang Y, Wu W, Xu L, Li X, Dou R. Vector analysis of low to moderate astigmatism with small incision lenticule extraction (SMILE): results of a 1-year follow-up. BMC Ophthalmol. 2015;15 (1). doi:10.1186/1471-2415-15-8

9. Pedersen IB, Ivarsen A, Hjortdal J. Changes in astigmatism, densitometry, and aberrations after SMILE for low to high myopic astigmatism: A 12-month prospective study. J Refract Surg. 2017;33 (1):11-17. doi:10.3928/1081597X-20161006-04

10. Ganesh S, Brar S, Pawar A. Matched population comparison of visual outcomes and patient satisfaction between 3 modalities for the correction of low to moderate myopic astigmatism. Clin Ophthalmol. 2017;11:1253-1263. doi:10.2147/OPTH.S127101

11. Dishler JG, Slade S, Seifert S, Schallhorn SC. Small-incision lenticule extraction for the correction of myopia with astigmatism: outcomes of the United States food and drug administration premarket approval clinical trial. Ophthalmology. 2020;127(8).

12. Ivarsen A, Hjortdal J. Correction of myopic astigmatism with small incision lenticule extraction. J Refract Surg. 2014;30(4):240-247. doi:10.3928/1081597X-20140320-02

13. Kobashi H, Kamiya K, Ali MA, Igarashi A, Elewa MEM, Shimizu K. Comparison of astigmatic correction after femtosecond lenticule extraction and small-incision lenticule extraction for myopic astigmatism. PLoS One. 2015;10(4):e0123408. doi:10.1371/journal. pone. 0123408

14. Chan TCY, Ng ALK, Cheng GPM, et al. Vector analysis of astigmatic correction after small-incision lenticule extraction and femtosecond-assisted LASIK for low to moderate myopic astigmatism. Br J Ophthalmol. 2016;100(4):553-559. doi:10.1136/ bjophthalmol-2015-307238

15. Hansen RS, Lyhne N, Grauslund J, Vestergaard AH. Small-incision lenticule extraction (SMILE): outcomes of 722 eyes treated for myopia and myopic astigmatism. Graefe's Arch Clin Exp Ophthalmol. 2016;254(2):399-405. doi:10.1007/s00417-015-3226-5
16. Zhang J, Wang $\mathrm{Y}$, Chen $\mathrm{X}$. Comparison of moderate-to high-astigmatism corrections using wavefront-guided laser in situ keratomileusis and small-incision lenticule extraction. Cornea. 2016;35(4):523-530. doi:10.1097/ICO.0000000000000782

17. Ganesh S, Brar S, Pawar A. Results of intraoperative manual cyclotorsion compensation for myopic astigmatism in patients undergoing small incision lenticule extraction (SMILE). J Refract Surg. 2017;33 (8):506-512. doi:10.3928/1081597X-20170328-01

18. Kang DSY, Lee H, Reinstein DZ, et al. Comparison of the distribution of lenticule decentration following SMILE by subjective patient fixation or triple marking centration. J Refract Surg. 2018;34 (7):446-452. doi:10.3928/1081597X-20180517-02

19. Xu J, Liu F, Liu M, et al. Effect of cyclotorsion compensation with a novel technique in small incision lenticule extraction surgery for the correction of myopic astigmatism. J Refract Surg. 2019;35 (5):301-308. doi:10.3928/1081597X-20190402-01

20. Taneri S, Kießler S, Rost A, Schultz T, Dick HB. Small-incision lenticule extraction for the correction of myopic astigmatism. J Cataract Refract Surg. 2019;45(1):62-71. doi:10.1016/j.jcrs.2018.08.030

21. Hiep NX, Khanh PTM, Quyet D, et al. Outcomes of small incision lenticule extraction for myopic astigmatic treatment. Open Access Maced J Med Sci. 2019;7(24):4272-4277. doi:10.3889/ oamjms.2019.373

22. Qian Y, Chen X, Naidu RK, Zhou X. Comparison of efficacy and visual outcomes after SMILE and FS-LASIK for the correction of high myopia with the sum of myopia and astigmatism from -10.00 to -14.00 dioptres. Acta Ophthalmol. 2020;98(2):161-172. doi:10.1111/ aos. 14078

23. Wan $\mathrm{T}$, Yin $\mathrm{H}$, Wu Z, Yang Y. Vector analysis of small incision lenticule extraction and toric implantable collamer lens implantation for astigmatism correction. [published online ahead of print, 2020 May 29]. Eur J Ophthalmol. 2020.

24. Kwak JJ, Jun I, Kim EK, Seo KY, Kim TI. Clinical outcomes of small incision lenticule extraction in myopia: study of vector parameters and corneal aberrations. Korean J Ophthalmol. 2020;34 (1):76-84. doi:10.3341/kjo.2019.0109

25. Alpins NA. A new method of analyzing vectors for changes in astigmatism. $J$ Cataract Refract Surg. 1993;19(4):524-533. doi:10.1016/S0886-3350(13)80617-7

26. Alpins NA. Vector analysis of astigmatism changes by flattening, steepening and torque. $J$ Cataract Refract Surg. 1997;23 (10):1503-1514. doi:10.1016/S0886-3350(97)80021-1

27. Alpins NA, Goggin M. Practical astigmatism analysis for refractive outcomes in cataract and refractive surgery. Surv Ophthalmol. 2004;49(1):109-122. doi:10.1016/j.survophthal.2003.10.010

28. Martinez M, Bartholomew M. What Does It "Mean"? A review of interpreting and calculating different types of means and standard deviations. Pharmaceutics. 2017;9(2):14. doi:10.3390/ pharmaceutics 9020014

29. Holladay JT, Dudeja DR, Koch DD. Evaluating and reporting astigmatism for individual and aggregate data. J Cataract Refract Surg. 1998;24(1):57-65. doi:10.1016/S0886-3350(98)80075-8

30. Reinstein DZ, Archer TJ, Randleman JB. JRS standard for reporting astigmatism outcomes of refractive surgery. J Refract Surg. 2014;30 (10):654-659. doi:10.3928/1081597X-20140903-01

31. Ivarsen A, Gyldenkerne A, Hjortdal J. Correction of astigmatism with small-incision lenticule extraction: impact of against-the-rule and with-the-rule astigmatism. $J$ Cataract Refract Surg. 2018;44 (9):1066-1072. doi:10.1016/j.jcrs.2018.06.029

32. Pérez-Izquierdo $R$, Rodríguez-Vallejo $M$, Matamoros $A$, et al. Influence of preoperative astigmatism type and magnitude on the effectiveness of SMILE correction. J Refract Surg. 2019;35 (1):40-47. doi:10.3928/1081597X-20181127-01 
33. Chow SSW, Chow LLW, Lee CZ, Chan TCY. Astigmatism correction using SMILE. Asia-Pacific J Ophthalmol. 2019;8(5):391-396. doi:10.1097/01.APO.0000580140.74826.f5

34. Chan TCY, Wan KH, Kang DSY, Tso THK, Cheng GPM, Wang Y. Effect of corneal curvature on optical zone decentration and its impact on astigmatism and higher-order aberrations in SMILE and LASIK. Graefe's Arch Clin Exp Ophthalmol. 2019;257(1):233-240. doi:10.1007/s00417-018-4165-8

35. Chen $\mathrm{P}$, Ye Y, Yu N, et al. Comparison of small incision lenticule extraction surgery with and without cyclotorsion error correction for patients with astigmatism. Cornea. 2019;38(6):723-729. doi:10.1097/ICO.0000000000001937

36. Köse B. Detection of and compensation for static cyclotorsion with an image-guided system in SMILE. J Refract Surg. 2020;36 (3):142-149. doi:10.3928/1081597X-20200210-01
37. Jun I, Kang DSY, Reinstein DZ, et al. Clinical outcomes of SMILE with a triple centration technique and corneal wavefront- guided transepithelial PRK in high astigmatism. J Refract Surg. 2018;34 (3):156-163. doi:10.3928/1081597X-20180104-03

38. Kobashi H, Kamiya K, Shimizu K. Dry eye after small incision lenticule extraction and femtosecond laser-assisted LASIK: meta-analysis. Cornea. 2017;36(1):85-91. doi:10.1097/ ICO.0000000000000999

39. Titiyal JS, Kaur M, Rathi A, Falera R, Chaniyara M, Sharma N. Learning curve of small incision lenticule extraction: challenges and complications. Cornea. 2017;36(11):1377-1382. doi:10.1097/ ICO.0000000000001323
Clinical Ophthalmology

\section{Publish your work in this journal}

Clinical Ophthalmology is an international, peer-reviewed journal covering all subspecialties within ophthalmology. Key topics include: Optometry; Visual science; Pharmacology and drug therapy in eye diseases; Basic Sciences; Primary and Secondary eye care; Patient Safety and Quality of Care Improvements. This journal is indexed on PubMed
Dovepress

Central and CAS, and is the official journal of The Society of Clinical Ophthalmology (SCO). The manuscript management system is completely online and includes a very quick and fair peer-review system, which is all easy to use. Visit http://www.dovepress.com/ testimonials.php to read real quotes from published authors. 